\title{
Principal Component-Based Logistical Regression Algorithms to Predict Health care Accessibility for Texas Medicaid Gap
}

Jinting Zhang ( $\boldsymbol{\nabla}$ whuzjt@whu.edu.cn )

Wuhan University https://orcid.org/0000-0001-8032-3317

Xiu Wu

Texas State University San Marcos: Texas State University

\section{Research}

Keywords: Medicaid gap, Health Access, Principal Components, Logistical Regression

Posted Date: July 15th, 2021

DOl: https://doi.org/10.21203/rs.3.rs-700790/v1

License: (c) (i) This work is licensed under a Creative Commons Attribution 4.0 International License.

Read Full License 


\title{
Principal Component-Based Logistical Regression Algorithms to Predict Health care Accessibility for Texas Medicaid Gap
}

\author{
Jinting Zhang ${ }^{1}$, Xiu $\mathrm{Wu}^{2} *$ \\ 1 School of Resource and Environmental Science, Wuhan University, Wuhan 430079, China; whuzjt@whu.edu.cn \\ 2 Department of Geography, Texas State University, San Marcos, TX 78666, USA. \\ *Correspondence; x_w10@txstate.edu Tel.: +(0)-512-781-0041
}

\section{Abstract \\ Background}

12 states without expanded Medicaid caused 2 million people who were under the poverty line across the U.S to be in Medicaid limbo and not eligible for subsidized health plans on the Affordable Care Act insurance exchanges. In order to amplify geographic equity, this paper aims to explore the health access for Medicaid gaps in Texas.

\section{Methods}

Principal Component-based logistical regression algorithms (PCA-LA) is provided data visualization and comparison in between unadjusted and adjusted Medicaid programs. Initially, Principal Component Analysis (PCA) eliminated well-known multiplicity problems between explanatory variables in the application of epidemiology. Optimized the traditional logistical Regression (LR), the PCA-LA method, is considered health status (HS) as a dependent variable with 0 ("poor" health) and 1 ("good" health), fourteen social-economic indexes as independent variables.

\section{Results}

After Principal Component Analysis (PCA), four composite components incorporated health conditions (i.e., "no regular source of care" (NRC), "Last check up more than a year ago" (LCT)), demographic impacts (i.e., four categorized adults (AS)), education (ED), and marital status (MS). Compared to the unadjusted LA, direct adjusted LA, and PCA-unadjusted LA three methods, the PCA - LA approach exhibited objective and reasonable outcomes in presenting an Odd Ratio (OR). They included that health condition is positively significant to HS due to beyond $1 \mathrm{OR}$, and negatively significant to ED, AS, and MS due to less than 1 OR.

\section{Conclusions}

This paper provided quantitative evidence for the Medicaid gap in Texas to extend Medicaid, exposed healthcare geographical inequity, offered a sight for the Centers for Disease Control and Prevention (CDC) to raise researchable direction of the Medicaid program and make a timely scientific judgment of Texas healthcare accessibility.

Keywords: Medicaid gap, Health Access, Principal Components, Logistical Regression

\section{Background}

Health care access is complicated, because not only emerging with different system constraints as well as depending on the complex healthcare needs, but also improving access resting on system-targeted facilitators, interventions, and policies [1]. Despite the adoption of universal healthcare coverage (UHC) by member countries of the World Health Organization (WHO), the U.S has the most expensive comparatively healthcare system in the world [2]. Ultimately, access to health care remains a major problem so that people are unable to access all the essential health services that they need. It is worth noting that providing scientifically explicit corroboration contributes to enlarge healthcare access. Medicaid is the largest common federal health care coverage program for low-income individuals of diverse ages in the United States and serves as a core institution that shapes public health crises, racial injustice, and electoral politics [3]. It was created by President Lyndon B. Johnson in 1965, as a unique approach in ensuring below poverty population gets free insurance coverage under federal and state provisions, playing a vital role in alleviating health inequities and reducing recidivism [4-7]. However, some regulations in Medicaid are restricted eligibility such as income, asset and age requirement, dependent children limitation, and categorical eligibility (pregnant women, 
children, and disabled people). Those lead to the Medicaid gap is increased and should be considered. The Medicaid gap is defined as those who do not have private insurance and unqualified Medicaid requirements. They are exposed to high risks of health care, social security, as well as vulnerability. In 2012, the Supreme Court ruled to allow states to opt-out of Medicaid expansion. In 2019, Affordable Care Act (ACA) was advocated for the population who earned less than 138 percent of the federal poverty guidelines (FPG), enlarging the number of Medicaid coverage. By 2020, there have been 2.5 million Americans living in the Medicaid gap in the U.S. Problematically, there are still 14 states that have not expanded Medicaid programs. Texas is one of 14 states that have not expanded Medicaid. In Texas, the Medicaid gap contains 20 million people, approximately $10 \%$ of the state's population, one more time of Medicaid (around 14 million). They might have a high potential risk of bad health care and health pressures. Hence, better recognition of the relevant health accessibility is beneficial to help those in the Medicaid gap address health inaccessibility, mitigate health conflictions, improve healthcare systems and future healthcare policymaking. To that end, Investigating the perspective of the Medicaid gap regarding the implementation of the Affordable Care Act is a timely and worthy question.

\section{Medicaid Gap States Map in the U.S}

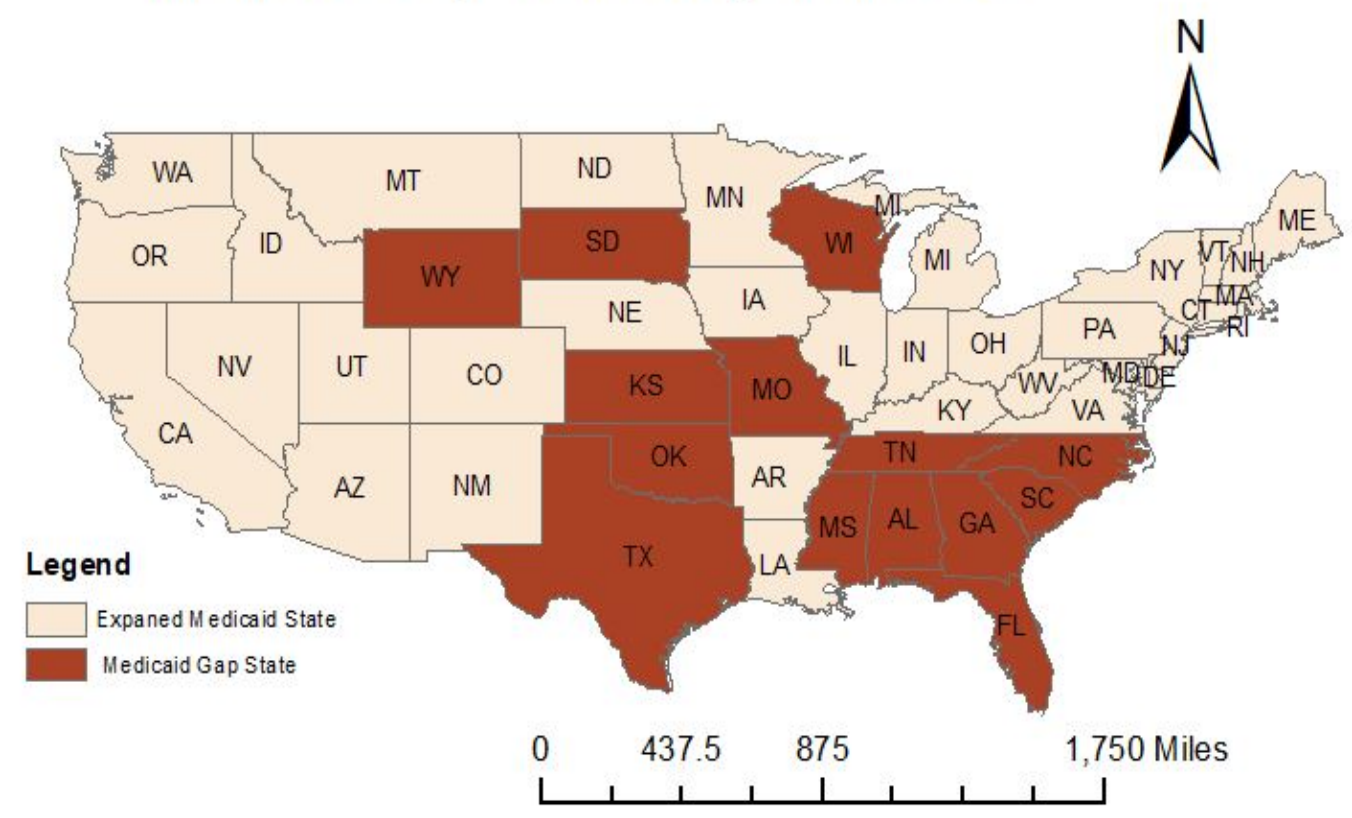

Fig 1. Medicaid gap Map in the U.S

The Medicaid gap is an ignored health care marginality between Medicaid and private insurance coverage in the U.S. Current literature provides limited information on the prevalence of Medicaid coverage gaps during the Pandemic. Most of the studies highlighted the policy adjustment from the qualitative analysis [8-11] except for Spencer et al. (2019). Despite health access for North Carolina Medicaid Gap Population was conducted in Statistical inference, population Characteristics by Poverty \& Insurance, cost barriers, healthy days, health status, and preventive care are well-documented, counter-comparative multi-variated indexes are not involved, instead of choosing univariate [12]. The study was conducted before the pandemic, limited to physical access in a short time, instead of emergency access and stable access in long run. Besides, potential risks of chronic diseases are not estimated in that research. Most importantly, multicollinearity issues are not mentioned and addressed in the context of rationale. It is a phenomenon that undermines the statistical significance of an independent variable, increases the standard deviation of variables, as well the inverse direction of coefficients. Health care Accessibility for Texas Medicaid Gap remedies those gaps 
based on social-economical assessment. Therefore, the purpose of this study was to identify the factors which determine health access for the Medicaid gap using a principal component-based logistical regression approach.

Although logistical regression is generally popular in the application of epidemiology, the effect of multicollinearity among variables in massive research was not eliminated in the regression model [13-15]. Since the primary principle of binary logistical regression (LA)is that there are no links between independent variables, correlation analysis between independent variables is necessary. Principal Component Analysis (PCA) is one of the effective ways to reduce dimensionality and minimize multicollinearity. Currently published articles of logistical regression based on PCA are focused on genome-wide association studies [16] and diseases research such as gestational diabetes mellitus [17] and nephropathy [18], which is hard to see in medical gap research. PCA-based LA health access analysis of the medical gap aims to compare comprehensive social-economic impacts between unadjusted conditions and adjusted conditions. It is beneficial to provide guidance about advocating ACA provisions and supply new sights of Medicaid policies, and equity evaluation of Medical Insurance systems.

2. Materials and Methods

2.1 Data collection and definitions

This research data stem from an annual, representative survey to show the health status and accessibility of health care for Texas Medicaid gap populations. Data on 63,083 cases from 2013 to 2020, including 8 years of questionnaires in table 1, were collected from The Behavioral Risk Factor Surveillance Survey (BRFSS), which is a national wide, random-digit-dial telephone survey. The questionnaire has three parts: 1) the core component, consisting of the fixed core, rotating core, and emerging core, 2) optional modules, and 3) state-added questions. Investigation contents involved demographic information, health behaviors information, access ways to care, and health quo. This study obtained Medicaid gap data for all registered 18-64 old people whose household income less than 138 percent of the federal poverty guidelines without any insurance during 2013-2019 in Texas from the Center for Health Statistics in the Texas Department of State Health Services (DSHS). The Medicaid gap addresses of all cases were geocoded to their exact geographic locations (latitudes and longitudes) by the Texas DSHS.

Table 1 Medical type table by years

Note type1- private insurance, type 2-Medicaid, type 3-Medicaid gap.

In this study, health status is the subject of observation as a unique dependent variable, which has two values such as 0 (i.e., health "fair" or "poor") and 1 (i.e., good health). Independent variables contain health conditions, demographic data, education, and economic conditions 14 variables in table 2. Health conditions refer to 7 variables such as "No regular source of care" (NRC), "Last check up more than a year ago" (LCT), "Could not see a doctor due to cost" (NSD), "Skipped medication due to cost" (SMC), "cardiovascular disease "(CVD), "Diabetes" (DT) and "Current smoker" (CS). Demographical data involve age structure, sex, race, and marital status. Economic conditions include employment (EM) and "Living with dependent children" (LDC). Educations consist of "Did not finish high school", "High school Graduate/GED", and "College Graduate" three scenarios. Three medical types are distributed in diverse variables in table 2.

Table 2 A-list of variables used for logistical regressions. 


\begin{tabular}{|c|c|c|c|c|c|c|c|}
\hline $\begin{array}{l}\text { Variable } \\
\text { Category }\end{array}$ & Predictors & Acronym & Value & $\begin{array}{l}\text { Above } \\
\text { poverty }\end{array}$ & Medicaid & $\begin{array}{l}\text { Medicaid } \\
\text { Gap }\end{array}$ & Interpretation \\
\hline \multicolumn{8}{|c|}{ Health Condition } \\
\hline & No regular source of care & NRC & 1 & $74.0 \%$ & $25.1 \%$ & $32.7 \%$ & No (Good) \\
\hline & No regular source of care & & 2 & $26.0 \%$ & $74.9 \%$ & $67.3 \%$ & Yes (Bad) \\
\hline & Last check up more than a year ago & $\mathrm{LCT}$ & 1 & $79.9 \%$ & $76.4 \%$ & $46.0 \%$ & No (Good) \\
\hline & Last check up more than a year ago & & 2 & $20.1 \%$ & $23.6 \%$ & $54.0 \%$ & Yes (Bad) \\
\hline & Could not see doctor due to cost & NSD & 1 & $76.6 \%$ & $81.6 \%$ & $48.1 \%$ & No (Good) \\
\hline & $\begin{array}{l}\text { Could not see a doctor due to the } \\
\text { cost }\end{array}$ & & 2 & $23.4 \%$ & $18.4 \%$ & $\mathbf{5 1 . 9} \%$ & Yes (Bad) \\
\hline & Skipped medication due to cost & $\mathrm{SMC}$ & 1 & $44.5 \%$ & $51.1 \%$ & $23.3 \%$ & No (Good) \\
\hline & Skipped medication due to cost & & 2 & $55.5 \%$ & $48.9 \%$ & $\mathbf{7 6 . 7} \%$ & Yes $(\mathrm{Bad})$ \\
\hline & Cardiovascular disease & CVD & 1 & $13.5 \%$ & $10.2 \%$ & $16.1 \%$ & Yes (Bad) \\
\hline & Cardiovascular disease & & 2 & $86.5 \%$ & $89.8 \%$ & $83.9 \%$ & No (Good) \\
\hline & Diabetes & DT & 1 & $18 \%$ & $31.7 \%$ & $42.6 \%$ & Yes (Bad) \\
\hline & Diabetes & & 2 & $82 \%$ & $68.3 \%$ & $47.4 \%$ & No (Good) \\
\hline & Current smoker & CS & 1 & $79.2 \%$ & $88.1 \%$ & $75.4 \%$ & No (Good) \\
\hline & Current smoker & & 2 & $20.8 \%$ & $11.9 \%$ & $24.6 \%$ & Yes (Bad) \\
\hline \multicolumn{8}{|c|}{ Demographic } \\
\hline & Age Structure & AS & 1 & $10.7 \%$ & $3.9 \%$ & $10.6 \%$ & Age $(<=25)$ \\
\hline \multirow{9}{*}{ Race } & Age Structure & & 2 & $23.4 \%$ & $12.6 \%$ & $47.3 \%$ & $\begin{array}{c}\text { Age }(>25 \text { and } \\
<=44)\end{array}$ \\
\hline & Age Structure & & 3 & $17.8 \%$ & $9.4 \%$ & $21.0 \%$ & $\begin{array}{c}\text { Age }(>44 \text { and } \\
<=55)\end{array}$ \\
\hline & Age Structure & & 4 & $48.1 \%$ & $74.2 \%$ & $21.2 \%$ & Age $(>55)$ \\
\hline & Sex & SEX & 1 & $34.7 \%$ & $45.3 \%$ & $36.3 \%$ & Male \\
\hline & Sex & & 2 & $65.3 \%$ & $54.7 \%$ & $63.7 \%$ & female \\
\hline & White & RACE & 1 & $30.9 \%$ & $50.0 \%$ & $34.3 \%$ & $\begin{array}{c}\text { Non-Hispanic } \\
\text { White }\end{array}$ \\
\hline & Hispanic & & 2 & $44.7 \%$ & $31.3 \%$ & $\mathbf{5 4 . 0} \%$ & Hispanic \\
\hline & Black & & 3 & $20.8 \%$ & $13.0 \%$ & $8.8 \%$ & $\begin{array}{c}\text { Non-Hispanic } \\
\text { Black }\end{array}$ \\
\hline & Other & & 4 & $3.6 \%$ & $5.7 \%$ & $2.9 \%$ & $\begin{array}{c}\text { Non-Hispanic } \\
\text { Other }\end{array}$ \\
\hline \multicolumn{8}{|c|}{ Economic Condition } \\
\hline & Employment & EM & 1 & $30.3 \%$ & $54.2 \%$ & $50.5 \%$ & Yes (Good) \\
\hline & Employment & & 2 & $69.7 \%$ & $45.8 \%$ & $49.5 \%$ & No (Bad) \\
\hline & Living with dependent children & LDC & 1 & $68.5 \%$ & $81.5 \%$ & $44.5 \%$ & No (Good) \\
\hline & Living with dependent children & & 2 & $31.5 \%$ & $18.5 \%$ & $55.5 \%$ & Yes (Bad) \\
\hline & College Graduate & $\mathrm{ED}$ & 1 & $45.1 \%$ & $44.2 \%$ & $28.6 \%$ & \\
\hline \multirow[t]{4}{*}{ Education } & High school graduate/GED & & 2 & $32.1 \%$ & $34.4 \%$ & $34.1 \%$ & \\
\hline & Did not finish high school & & 3 & $22.7 \%$ & $21.4 \%$ & $\mathbf{3 7 . 3} \%$ & \\
\hline & Marital status & MS & 1 & $32.1 \%$ & $60.0 \%$ & $35.4 \%$ & married \\
\hline & Marital status & & 2 & $67.9 \%$ & $40.0 \%$ & $64.6 \%$ & single \\
\hline Dependent & Health status & & 1 & $67.3 \%$ & $82.1 \%$ & $27.5 \%$ & good \\
\hline Variable & Health status & & 0 & $32.7 \%$ & $17.9 \%$ & $\mathbf{7 2 . 5} \%$ & poor or fair \\
\hline
\end{tabular}




\subsection{Study Area}

In this study, study Areas are categorized by above poverty, Medicaid, and Medicaid gap three insurance types in 13 regions in figure 2. 1 represents Great Houston Metropolitan Statistical Area (MSA), which contains Austin, Brazoria, Chambers, Galveston, Harris, Liberty, Montgomery, Matagorda, and Wharton 9 counties. 2 represents Fort Bend County, 3 represents Dallas-Plano-Irving MSA, which contains Collin, Dallas, Delta, Denton, Ellis, Hunt, Kaufman, and Rockwall 8 counties. 4 represents Ft. Worth-Arlington MSA, which cover Hood, Johnson, Parker, Somervell, Tarrant, Wise 7 counties. 5 represents Bexar County. 6 represents Travis County, 7 represents Lubbock-Cooper ISD, 8 represents Midland-Odessa MSA, including Martin, Midland, and Ector, 9 represents Northeast Texas Public Health District, including Smith, Gregg, Wood, Rains, Van Zandt, Henderson, Anderson 7 counties. 10 represents El Paso MSA, including El Paso and Hudspeth two counties. 11 represents McAllen-Edinburg-Mission MSA, including Hidalgo County, 12 represents remaining metropolitan, including 36 counties. 13 represents the remaining 179 counties.

Fig 2. Medicaid Gap District distribution in TX

Table $3 \quad$ Medical type distribution table

\begin{tabular}{|c|c|c|c|c|c|}
\hline \multirow{2}{*}{ Count } & \multirow{2}{*}{ Region } & \multicolumn{3}{|c|}{ Medicaid type } & \multirow{2}{*}{ Total } \\
\hline & & \multicolumn{2}{|c|}{ Above-povertyTraditional } & $\begin{array}{c}\text { Medicaid } \\
\text { Gap }\end{array}$ & \\
\hline 1 & Houston & 2167 & 272 & 209 & 2648 \\
\hline 2 & Fort Bend County & 394 & 6 & 6 & 406 \\
\hline 3 & Dallas & 3672 & 192 & 138 & 4002 \\
\hline 4 & Ft. Worth & 2330 & 179 & 102 & 2611 \\
\hline 5 & Bexar county & 3255 & 366 & 293 & 3914 \\
\hline 6 & Travis & 6177 & 426 & 294 & 6897 \\
\hline 7 & Lubbock & 572 & 179 & 80 & 831 \\
\hline 8 & Midland-Odessa & 519 & 147 & 80 & 746 \\
\hline 9 & Northeast Texas & 553 & 158 & 127 & 838 \\
\hline 10 & El Paso MSA & 1799 & 318 & 292 & 2409 \\
\hline 11 & McAllen Edinburg & 1568 & 354 & 493 & 2415 \\
\hline 12 & Remaining Metropolitan & 13143 & 865 & 695 & 14703 \\
\hline 13 & Remaining County & 18605 & 1153 & 905 & 20663 \\
\hline Total & & 54754 & 4615 & 3714 & 63083 \\
\hline
\end{tabular}

\subsection{Study Framework}

According to Texas Medicaid yearly income limits standard, the Medicaid gap is defined as those whose income less than $\$ 35000$ per family with one person (or $\$ 47000$ with two-person) without any insurance. Then, we conduct the inter-correlations among independent variables before performing PCA. If correlations exist, we extracted related factors of health status by PCA, otherwise directly recode related independent 
variables to model the LR. Via the comparison of unconditional requirements and adjusted requirements, accordingly, the distinctions are automatically revealed the pros and cons of the ACA policy in Texas. The study framework is in Fig.3.

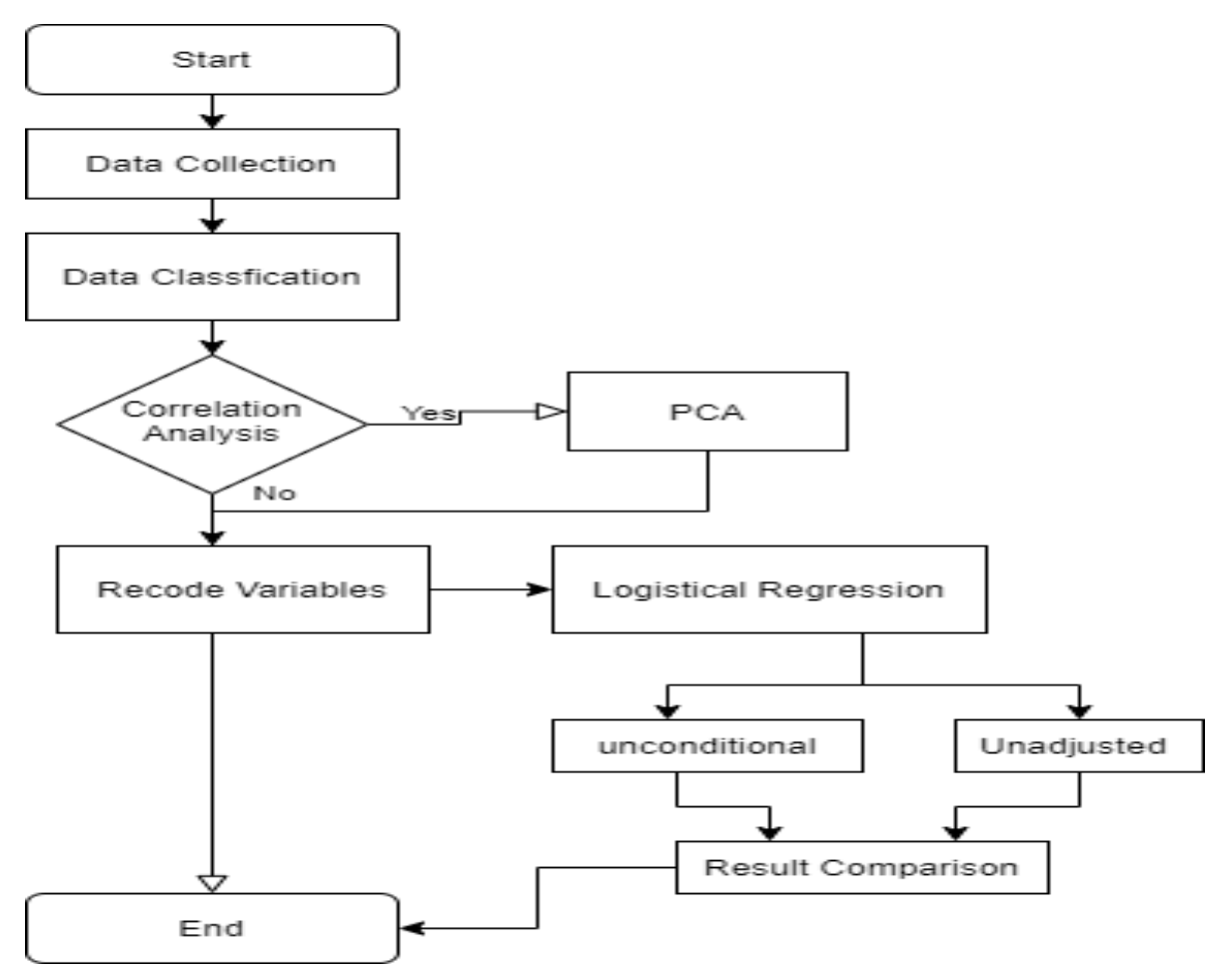

Fig 3. Study Framework

\subsection{Method}

Logical regression is used for a broad range of research applications, especially popular with medical research in which the dependent variable is binary format outcome of either 0 or 1 , true or false, yes or no, high or low. The general mathematical equation of logistical regression is written as follows, where $\mathrm{Y}$ is the dependent variable based on $\mathrm{X}_{1}, \mathrm{X}_{2}[19]$.

$$
Y=C+B_{1} X_{1}+B_{2} X_{2}+\ldots .
$$

In this research, firstly, standardize the matrix $\mathrm{X}$ with independent variables into $\mathrm{X} *$. Then, extract $\mathrm{r}$ number of principal components under the condition of $\mathrm{r}$ number of the sum of eigenvalue beyond 1 . After that, the orthogonal matrix $\beta$ with eigenvector was divided as $\beta=(\beta 1 \mid \beta 2)$, so r number of values are presented as $\mathrm{Z} 1=\mathrm{X} * \beta 1$, the following equation is calculated.

$$
Z_{j}=\sum_{i}^{r} l_{i j} X_{i} \quad \mathrm{j}=1,2, \ldots, \mathrm{r}
$$

Where $\mathrm{Z}_{1}, \mathrm{Z}_{2}, \ldots \ldots \ldots \mathrm{Z}_{\mathrm{r}}$ are viewed as diversely extracted factors. The relationship between factors equals 0 so that those factors are defined as independent variables. According to logistic regression is a classification algorithm, the assumption is that the coefficients of factors equal to a1, a2, ......ar, the model is created as follows:

$$
\begin{gathered}
P(y=1 \mid z)=\frac{e^{a_{0}}+\sum_{i=1}^{r} \lambda_{i} X_{i}}{1+e^{a_{0}}+\sum_{i=1}^{r} \lambda_{i} X_{i}} \\
\lambda_{\mathrm{i}}=l_{i}^{r} a=l_{i 1} a_{1}+l_{i 2} a_{2}+\ldots+l_{i r} a_{r} \mathrm{i}=1,2, \ldots \ldots \mathrm{p}
\end{gathered}
$$


We should conduct the Wald test after getting $\lambda_{\mathrm{i}}$. In light of SPSS statistical software, the covariance matrix is calculated by the following equation.

$$
=\left(\begin{array}{ccc}
\operatorname{var}(\alpha) & \operatorname{cov}\left(\alpha_{1}, \alpha_{2}\right) & \ldots \ldots \operatorname{cov}\left(\alpha_{1}, \alpha_{r}\right) \\
\ldots & \ldots & \ldots \\
\operatorname{cov}\left(\alpha_{r 1}, \alpha_{1}\right) & \operatorname{cov}\left(\alpha_{r}, \alpha_{2}\right) & \ldots \ldots \operatorname{var}\left(\alpha_{r}\right)
\end{array}\right)
$$

In light of the assumption of the likelihood ratio, $\alpha^{r}=\left(\alpha_{1}, \alpha_{2}, \ldots \ldots, \alpha_{r}\right)$ is met by a normal distribution. It leads to $\lambda$ qualified for normal distribution result from normal distribution has characteristic of stationary in linear transformation. When the covariance of $\lambda$ is captured, we will get the Wald test in the context of $\lambda=0$ using the following equation.

$$
\mu_{i}=\frac{\lambda_{i}}{\sqrt{\operatorname{var}\left(\lambda_{i}\right)}}
$$

If parts of independent variables are inter-correlated, we just employed PCA to remove the association between a part of variables based on the above steps [20]. The setting of the threshold value is a very important aspect of logistic regression, 0.6 is defined as the threshold value in this study.

\section{Results}

3.1 Sample description

3.1.1 Health care access

Medicaid gap has the worst health care access among all insurance coverages, in which the high percentage of "bad" answers of the following variables, including: "fair or poor" health of $72.5 \%$ in Medicaid gap are far beyond that of either above-poverty (32.7\%) or Medicaid (17.9\%). "no regular source of care" of $67.3 \%$ is higher than that of above-poverty, lower than Medicaid (74.9\%); "last check up more than a year ago" of $54 \%$ is the highest in three insurance types (20.1\% above-poverty, $23.6 \%$ Medicaid, $54 \%$ Medicaid gap); $51.9 \%$ of "Could not see doctor due to cost " is took up the highest among three insurance types( $23.4 \%$ above-poverty, $18.4 \%$ Medicaid, $51.9 \%$ Medicaid gap); "Skipped medication due to cost" of $76.7 \%$ is occupied the number one among three insurance types( $55.5 \%$ above-poverty, $48.9 \%$ Medicaid, $76.7 \%$ Medicaid gap); "Cardiovascular disease" of $16.1 \%$ is took up the highest among three insurance types( $13.5 \%$ above-poverty, $10.2 \%$ Medicaid, $16.1 \%$ Medicaid gap); Diabetes of $42.6 \%$ is the highest among three insurance types (18\% above-poverty, $31.7 \%$ Medicaid, $42.6 \%$ Medicaid gap). "Current smoker" of $24.6 \%$ is occupied the number one among three insurance types (20.8\% above-poverty, $11.9 \%$ Medicaid, $24.6 \%$ Medicaid gap).

\subsubsection{Demographic Status}

The disparity of demographic in Medicaid gap is more compelling than other insurance groups for three aspects. First, according to statistical investigations in table 2, on average, individuals in the Medicaid gap were younger (48.8 years) than either traditional Medicaid (59.9 years), but less than above-poverty Texan (54.0 years). The age distribution in the Medicaid gap is concentrated on those who are more than 25 and less than 44. On the contrary, the age distribution in above poverty and Medicaid are congregated on people who are beyond 55 years old. Second, the female population in Medicaid gap of $63.7 \%$ are higher than either the above-poverty group or Medicaid group, even though the male weight of $36.3 \%$ is higher than $34.7 \%$ of the above-poverty group, but less than 45.3 of the Medicaid population. At last, the Hispanic population of $50.4 \%$ in Medicaid gap is higher than that of Medicaid and above-poverty, compared to the non-Hispanic population.

3.1.3 Economic, educational, and marital status

The Medicaid gap has a higher vulnerability than the above-poverty group and Medicaid concerning economic, education, and marital status. First, the Medicaid gap has not a good economic condition as regards of two sides. $49.5 \%$ of those who were unemployed in the Medicaid gap is higher than $45.8 \%$ of Medicaid and lower than $69.7 \%$ of the above-poverty group. On the other hand, $55.5 \%$ of Living with dependent children is the highest among three groups (31.5\% above-poverty, $18.5 \%$ Medicaid, $55.5 \%$ Medicaid gap). Second, $37.3 \%$ of "Did not finish high school" in Medicaid gap are higher than either the above-poverty group (22.7\%) and the Medicaid group (21.4\%), meaning the Medicaid gap had lower educational attainment. Finally, $64.6 \%$ of a single person in Medicaid gap are lower than $67.9 \%$ of the above-poverty group 
but higher than $40 \%$ of the Medicaid group. The Medicaid gap has beyond a half portion of single persons of loneliness, which results in inhibited sociability problems [21] or mental health issues [22].

3.1.5 space-time sample change

From a spatial distribution perspective, 63083 samples are categorized into 3714 individuals in the Medicaid gap, 4615 individuals in Medicaid, and 54754 individuals in above-poverty. The Metropolitan area accounted for 41176 cases while the rural area is occupied 21907 cases. Samples of this research relied on metropolitan observation. During 2013-2020, the Medicaid gap is collected 4911 cases, while above-poverty had 6726 cases, as well as Medicaid, owned 51446 cases. It indicates sample distribution is yearly unbalanced in three insurance types and Medicaid is overweighted than other insurances in the procedure of sample collections.

3.2 Correlation

Before checked of correlations, all independent variables should be standardized to have a mean of 0 and a standard deviation of 1 (unit variance). In light of table 4, 14 explanatory variables are significant to the dependent variable of HS due to a $\mathrm{p}$-value less than 0.05 . Nevertheless, if independent variables are not significant to each other, they also should be eliminated before conducting the PCA. In this study, SEX, Race, EM, CVD, DT are not significant to connect other variables. They admittedly do not participate in modeling LR models. Meanwhile, the rest of the nine independent variables have correlated with each other due to coefficients not equal to zero. That is why we choose the PCA to create new uncorrelated variables that successively maximize variance.

3.3 PCA analysis

Based on correlation analysis, we perform nine explanatory variables to extract component factors using PCA. The dataset was examined using Kaiser-Meyer-Olkin (KMO) and Bartlett's Test of Sphericity. The KMO test compares the correlation statistics to identify if the variables include sufficient differences to extract unique factors. A KMO value of 0.56 for nine explanatory variables is more than the cutoff value of 0.7. The Bartlett's Test of Sphericity (BTS) value of 0.0 was significant $(\mathrm{p}<0.001)$, validating that correlation between variables does exist in the population. Communality is a common variance between 0 and 1 , using the remaining variables as factors, which was used to determine if any variables should be excluded from the factor analysis (Table 5). A 0.7 cutoff is used to determine the significance of explanatory variables. Using an eigenvalue threshold greater than 1.0, four factors are identified that could explain a cumulative $64.7 \%$ of the variance after 6 iterations (Figure 3). A varimax rotation was used to assist in the interpretation of the PCA analysis. The rotated component matrix was examined for variables with a cutoff of 0.7 . Table 5 gave us the direct relationship between factors and explanatory variables. The first factor represents high loading on variables related to LCT and NRC, which have high similarities, indicating the HS is positively related to health conditions. Factor 2, called the education index, is positively related to the population who reached various degrees. Factor 3 represents age structure, which is negatively related to HS, meaning the elder people have worse health status. Factor 4 was the marital status index, positively affecting HS.

Table 4 Correlation Table 


\begin{tabular}{|c|c|c|c|c|c|c|c|c|c|c|c|c|}
\hline Acronym & NRC & LCT & NSD & SMC & CS & AS & SEX & RACE & EM & LDC & ED & $\mathrm{M}$ \\
\hline NRC & $1 / 0.00$ & & & & & & & & & & & \\
\hline LCT & $-0.53 / 0.00$ & & & & & & & & & & & \\
\hline NSD & $0.25 / 0.00$ & $0.24 / 0.00$ & & & & & & & & & & \\
\hline SMC & $0.10 / 0.00$ & $0.01 / 0.04$ & $0.27 / 0.00$ & & & & & & & & & \\
\hline CS & $-0.08 / 0.00$ & $0.10 / 0.00$ & $0.14 / 0.00$ & $0.06 / 0.00$ & & & & & & & & \\
\hline AS & $-0.17 / 0.00$ & $-0.27 / 0.00$ & $-0.16 / 0.00$ & $-0.23 / 0.00$ & $-0.03 / 0.00$ & & & & & & & \\
\hline SEX & $0.04 / 0.00$ & $-0.07 / 0.00$ & $0.11 / 0.00$ & $0.02 / 0.00$ & $-0.05 / 0.00$ & $0.01 / 0.0 .3$ & & & & & & \\
\hline RACE & $0.02 / 0.04$ & $0.04 / 0.00$ & $0.08 / 0.00$ & $0.19 / 0.00$ & $0.02 / 0.00$ & $-0.15 / 0.00$ & $0.01 / 0.1$ & & & & & \\
\hline EM & $0.09 / 0.00$ & $-0.14 / 0.00$ & $-0.02 / 0.00$ & $0.14 / 0.00$ & $-0.02 / 0.00$ & $0.27 / 0.00$ & $0.17 / 0.00$ & $-0.03 / 0.00$ & & & & \\
\hline LDC & $0.11 / 0.00$ & $0.16 / 0.00$ & $0.16 / 0.00$ & $0.17 / 0.00$ & $-0.00 / 0.03$ & $-0.44 / 0.00$ & $0.13 / 0.00$ & $0.11 / 0.00$ & $-0.17 / 0.00$ & & & \\
\hline ED & $0.18 / 0.00$ & $0.13 / 0.00$ & $0.15 / 0.00$ & $0.29 / 0.00$ & $0.10 / 0.00$ & $-0.04 / 0.00$ & $0.04 / 0.00$ & $0.13 / 0.00$ & $0.06 / 0.00$ & $0.16 / 0.00$ & & \\
\hline MS & $-0.07 / 0.00$ & $0.47 / 0.00$ & $0.10 / 0.00$ & $0.17 / 0.00$ & $0.12 / 0.00$ & $-0.14 / 0.00$ & $0.10 / 0.00$ & $0.10 / 0.00$ & $0.06 / 0.00$ & $-0.09 / 0.00$ & $0.06 / 0.00$ & \\
\hline CVD & $-0.07 / 0.00$ & $0.07 / 0.00$ & $-0.03 / 0.00$ & $-0.03 / 0.00$ & $-0.02 / 0.00$ & $-0.09 / 0.00$ & $0.05 / 0.00$ & $-0.01 / 0.24$ & $-0.15 / 0.00$ & $0.05 / 0.00$ & $-0.03 / 0.00$ & $0.01 /$ \\
\hline DT & $-0.21 / 0.00$ & $0.02 / 0.00$ & $-0.14 / 0.00$ & $0.01 / 0.00$ & $0.02 / 0.00$ & $-0.06 / 0.00$ & $-0.01 / 0.00$ & $-0.13 / 0.00$ & $-0.09 / 0.00$ & $0.00 / 0.7$ & $-0.23 / 0.00$ & $0.03 /$ \\
\hline HS & $-0.19 / 0.00$ & $-0.04 / 0.00$ & $0.22 / 0.00$ & $0.20 / 0.00$ & $0.05 / 0.00$ & $-0.1 / 0.00$ & $0.02 / 0.00$ & $-0.1 / 0.00$ & $0.12 / 0.00$ & $0.04 / 0.00$ & $-0.21 / 0.00$ & $-0.11 /$ \\
\hline
\end{tabular}

Component Plot in Rotated Space

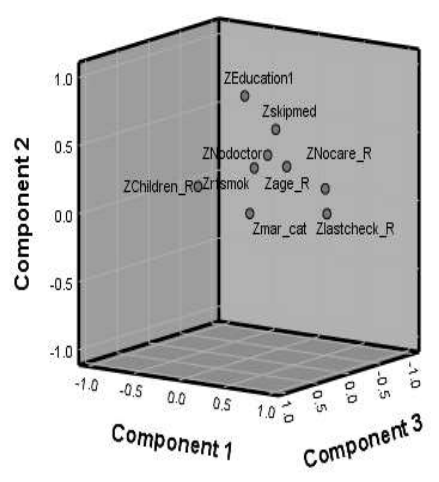

Fig 3 Component Structure

Table $5 \quad$ Varimax with Kaiser Normalization Rotated principal component analysis. 


\begin{tabular}{ccrrrr}
\hline \multirow{2}{*}{ Acronym } & Extraction & \multicolumn{3}{c}{ Component } \\
LCT & 0.849 & $\mathbf{0 . 9 1 7}$ & 0.053 & 0.072 & -0.010 \\
NRC & 0.878 & $\mathbf{0 . 9 0 3}$ & 0.236 & 0.078 & 0.032 \\
ED & 0.672 & -0.030 & $\mathbf{0 . 8 1 6}$ & 0.023 & -0.073 \\
SMC & 0.492 & 0.283 & 0.595 & -0.021 & 0.236 \\
NSD & 0.274 & 0.257 & 0.417 & 0.070 & 0.171 \\
AS & 0.792 & -0.168 & 0.159 & $-\mathbf{0 . 8 4 0}$ & -0.185 \\
LDC & 0.765 & -0.018 & 0.262 & 0.682 & -0.289 \\
MS & 0.751 & 0.061 & -0.031 & 0.074 & $\mathbf{0 . 8 6 1}$ \\
CS & 0.356 & -0.029 & 0.265 & -0.127 & 0.518 \\
\hline
\end{tabular}

\subsection{Regression Analysis}

This research was considered two scenarios in the context of three various insurance coverage conditions, consisting of logistical regression models based on PCA outcomes and direct logistical models. Each scenario was also reflected diverse impacts on the independent variable in unadjusted or adjusted Medicaid policies. We simultaneously got a clear comparison between having PCA and without PCA and distinction in principle factors of currently unadjusted impacts and impacts after adjustment via table 6 .

\subsubsection{Health conditions}

Through PCA, factor 1 in table 6 interpreted health condition change regarding LCT and NRC. It is the most remarkable among factors. From the NRC perspective, despite the value in traditional Medicaid is not significant to health status owing to $\mathrm{p}$-value beyond 0.05 , the $\mathrm{P}$-values in beyond poverty and Medicaid gap are less than 0.01 , indicating the value are statistically significant. In beyond poverty group, OR value equals 1.33 response to "no" as referent group in terms of "No regular source of care", meaning those who had private insurances, but no regular check-up sources had a $133 \%$ higher chance of health risks when compared with people who had a regular source of care within private insurances conditions and $95 \%$ Confidence Interval (CI). In the Medicaid gap, OR value is 1.37 under CI 95\%, implying those who did not have insurances and regular check-up sources had a 137\% higher chance of health risks when compared with people who had a regular source of care in the Medicaid gap group. Most importantly, OR values under CI 95\% are over 1 in beyond poverty and Medicaid gap situations, including two folds. One means the case increase of "No regular source of care" leads to a rise of the probability of health improvement, the other is the outcomes of HS after adjustment tends to 1 (i.e., good health). At the same time, OR value of 1.37 in the Medicaid gap and CI $95 \%$ is higher than OR value of 1.33 in the beyond poverty group, portraying the group of Medicaid gap is more vulnerable than the group who have private insurances. Through comparisons of adjusted outcomes in having PCA and without PCA, OR value of 3.29 of private insurance coverage in the direct LA model is higher than 1.33 in implementing PCA-LA, and 5.8 OR value of Medicaid gap in the direct LA model are higher than 1.37 in implementing PCA in response to referents, assuming that biased co- efficient estimates or very large standard errors for the logistic regression coefficients are hidden in the models [23]. From the LCT perspective, the difference of the LA model between having PCA and without PCA is a direction change. OR value is less than 1 in the before PCA model, meaning LCT is negatively significant to HS and the values tend to 1 (i.e., good health). Conversely, OR value is beyond 1 in the after PCA model, meaning LCT positively affects HS and the value tends to 0 (i.e.," fair or poor "health).

3.4.2 Demographic impacts

Factor 2 after PCA in table 6 is defined as the demographical adjustment of AS. The referent is those whose age is less than 25. The predictors of AS under CI 95\% are significant to HS in the above-poverty and Medicaid gap two groups, except for Medicaid, due to $\mathrm{p}$-value less than 0.01. As in previous PCA analysis, AS is identified as a unique impact factor, The OR value under CI $95 \%$ is similar in the direct unconditional LA and the unadjusted PCA-LA, meaning recoding AS is not necessary. In the above-poverty group, the 
OR values of ( 0.08 in PCA-LA, 0.23 in the direct LA) those whose ages are more than 55 are the lowest OR values among four age levels under CI $95 \%$. It means the beyond 55 old people are the most vulnerable group in four various age groups. In the same vein, more than 55 old people are the highest risk group of health care in the Medicaid gap. The OR values toward 0 of HS (i.e., "fair or poor" health), describing after adjusted the insurances policy, AS increasing leads to a decline of the possibility of health risks. Base on OR decay, OR values are shown a linear attenuation regardless of insurance types.

3.4.3 Education impacts

Factor 3 in table 6 points to education impacts. Those who already college graduate are viewed as referents. All predictors of AS under CI 95\% are significant to HS in three insurance types, except for PCA-LA in the Medicaid insurance group. According to PCA analysis, ED is extracted as a unique impact factor due to beyond 0.7 threshold, The OR value under CI $95 \%$ is identical in the direct unconditional LA and the unadjusted PCA-LA, meaning recoding AS is not necessary. In three insurance types, the OR values in those who have not finished high school degree or passed GED are the lowest OR values, meaning they have the highest health risks results from OR less than 1. The OR values toward 0 of HS (i.e., "fair or poor" health), describing after adjusted the insurances policy, ED increasing triggers a decline of the possibility of health risks. In addition, Medicaid gap changes are more remarkable than the other two insurances after adjustment since the OR values are higher than the other two groups.

3.4.4 Marital Status impacts

Factor 4 in table 6 refers to marital status impacts. Those who are married are regarded as referents. MS is a dichotomous independent variable. Interestingly, although the directly adjusted LA model is of no significance in the above-poverty and Medicaid gap, the PCA-LA is significant in the context of three insurances. According to PCA analysis, MS is extracted as a unique impact factor due to beyond 0.7 threshold, The OR value under CI $95 \%$ is identical in the direct unconditional LA and the unadjusted PCA-LA, meaning recoding MS is not necessary. After PCA analysis, the OR values in three insurance types in PCA-LA models are lower than the unadjusted OR, demonstrating it is essential to implement some other variables to control. Furthermore, those who are single had higher health risks, compared to married people. The reason is that the OR value is less than 1 . The OR values toward 0 of HS (i.e., "fair or poor" health), describing after adjusted the insurances policy, MS increasing stimulates a decline of the possibility of health risks. In addition, the change after adjustment in the Medicaid gap is more remarkable than the other two insurances since the OR values are higher than the other two insurances.

4. Discussion

The purpose of PCA is to find out related the Medicaid gap health access sensitive factors, the LA Modeling aims to compare health access divergences in the Medicaid gap between before and after ACA policy adjustments. To begin with, the current problems in Texas are not just multiple chronic illnesses, but also health barriers. The Medicaid gap reports more multiple chronic conditions than the traditional Medicaid group in terms of two aspects. On one hand, the highest risk of multiple chronic conditions inferred that most Medicaid gap population health is faced up more serious health crises without insurance coverage than the traditional Medicaid. On the other hand, they have been the unhealthy status for a long time for lack of immediate therapies, which leads to complex medical needs. Notably, the Medicaid gap existed higher rates of access barriers than that of either the above-poverty group or the traditional Medicaid population, which directly leads to large, missed opportunities for preventive care of chronic diseases. There is a consensus of preventive services that could reduce health care expenses by early interventions to avoid disease worsening [24-25]. Second, economic hardship trip over the capability of the Medicaid gap. The Hispanic population makes up the highest percentage in Texas $(50.4 \%)$, and females are occupied $63.7 \%$ in the Medicaid gap, while the proportion of living with dependent children in the Medicaid gap is $55.5 \%$, the highest among the three categories. Those in the Medical gap also account for the highest percentage $(37.3 \%)$ to report not finishing high school. On other hand, the high unemployment rate in the Medicaid gap made them could not afford self-sufficiency. Most Importantly, those in the Medicaid gap population were reported having employment more than the traditional Medicaid population, while the percentage of married Medicaid gap is higher than the traditional Medicaid gap. That illustrates they work hard for their family, ignoring their health benefit requirements. In addition, they pay attention to their earnings when they look for a job, not do much thinking of benefits needs. After the expansion of Medicaid, the health access in Medicaid gap is underlyingly broad in Texas. Especially, health warranty for the vulnerable population is dramatically improved. 
By comparison of direct LA and PCA-LA, ACA adjustment in Texas could mitigate health pressure in the Medicaid gap and reduced health inequities [26-27]. First, health conditions directly positive impacts on good health status in the Medicaid gap. Thanks to OR value beyond 1, after the adjustment of the ACA policy, the Medicaid gap is bound to enter the Medicaid group so that some who do not have insurance could participate in the free insurance coverage system, saving more lives and reliving more suffering. Second, demographic impacts focus on beyond 55-year-old people who will have a decreased possibility of health risks after the adjustment. Third, education impacts are negative related to HS, the adjustment will assist people who have not finished high school degree in Medicaid gap to have more opportunities to access the Medicaid system and reduce health risks. Eventually, Marital Status is a negative influence on HS. Texas participating in the ACA program will benefit a single person in the Medicaid group, especially single women, to improve health care conditions and get more chances to access the Medicaid program.

Beyond the statistical significance of the Medicaid gap, we are further aware that the deep root of the decline of Medicaid expansion is not about financial limits, but about the political contest. We called "Politics of Medicaid", which means democratic states asserting Medicaid importance when republic states holding Medicaid cuts [28]. When standing at marginal in a polity, the Medicaid gap has to stop to think about how policy and political vulnerability [29]. Indeed, the deep root relies on federalism. Medicaid is the epitome of how federalism produces inequity by constructing geographical disparity in access to vital healthcare resources [28]. As a boon, Medicaid is a program that saves thousands of lives each year and rendered tens of millions of Americans with free security of health insurance [30]. Geographical inequities between beneficiaries and the Medicaid gap are the product of policy choices made possible by federalism. Despite federalism is not good inherently, it is inevitable to see that federalism triggers mechanism injustice among economically and racially marginalized Americans and shapes the political effects of Medicaid policy.

5. Conclusions

5.1 Implication

Based on conventional LA, The PCA-LA health access research for Medicaid gap added PCA to eliminate multicollinearity disruption, emulated disparity of the Medicaid gap in Texas, visualized the domain concerns of healthcare, education, economic, demographic impacts. Hence, it provides powerful evidence to improve the Medicaid program. Expansion of Medicaid, simultaneously, may result in both safer health behavior and outcomes for the Medicaid gap. Furthermore, the research quantified the contribution of government and the public sector, the roles of markets and the private sector, and the overlap of the public and private sector work [31]. Hence, assessing access to health services for the Medicaid gap could have a positive impact on the future health care of Texas. It also lays the groundwork for recognizing all the dimensions and complexities of healthcare access in Texas [32].

5.2 Limitations

This research has several limitations due to the healthcare statistic. First, based on the BRFSS dataset, this study has inevitable misclassifications when sorting out. Medicaid samples are higher than the other two groups. A balanced number of samples will increase the accuracy of the analysis of the Medicaid gap. On the other hand, misclassifications are hidden in the standard of Medicaid. the FTP is defined as annual income between $\$ 20000-\$ 21404$ in Texas. Due to the dynamic Texas FPG criteria, representative samples are divided into eight income categories. There are $\$ 1404$ statistical errors in annual household income. In addition, one index covers many variables, such as multiple Chronic Conditions. Unmatched Variable names may lead to missing data, affecting exact statistical results. Lastly, there is missingness in three variables in the statistic period. Variables missing may lead to estimate value is not accurate.

Although the Medicaid gap is marginal in the U.S, we sufficiently use quantitative methods to health access for Medicaid gap. Even Medicaid is a political issue, this research is useful to local government, the Centers for Disease Control and Prevention (CDC) to estimate Medicaid program implementation consequences by describing how their efforts in the long term can serve towards the improvement of health and socio-economic outcomes [33].

Table 6. Logistic regression analysis results - Medicaid gap 


\begin{tabular}{|c|c|c|c|c|c|c|}
\hline & & & unadjusted & adjusted & PCA-unadjusted & PCA-adjusted \\
\hline Variable/Factor & $\begin{array}{c}\text { No. of } \\
\text { Patients } \\
(\%)\end{array}$ & $\begin{array}{c}\text { No. of } \\
\text { Patients } \\
(\mathrm{N})\end{array}$ & OR $(95 \% \mathrm{CI})^{a}$ & $\operatorname{aOR}(95 \% \mathrm{CI})^{\mathrm{b}}$ & $\operatorname{aOR}(95 \% \mathrm{CI})^{\mathrm{c}}$ & $\operatorname{aOR}(95 \% \mathrm{CI})^{\mathrm{d}}$ \\
\hline \multicolumn{7}{|l|}{ No regular source of care } \\
\hline \multicolumn{7}{|l|}{ Above-poverty } \\
\hline $\mathrm{NO}-1$ & $74.0 \%$ & 4046 & 1.00 (referent) & 1.00 (referent) & 1.00 (referent) & 1.00 (referent) \\
\hline YES-2 & $26.0 \%$ & 1419 & $1.9[1.68,2.19] *$ & $3.29[2.1,5.12] *$ & $1.7[1.54,1.9] *$ & $1.33[1.16,1.53] *$ \\
\hline \multicolumn{7}{|l|}{ Traditional Medicaid } \\
\hline $\mathrm{NO}-1$ & $25.1 \%$ & 12582 & 1.00 (referent) & 1.00 (referent) & 1.00 (referent) & 1.00 (referent) \\
\hline YES-2 & $74.9 \%$ & 37468 & $1.02[0.97,1.08]$ & $1.56[0.98,2.48]$ & $1.56[0.97,2.52]$ & $1.18[0.64,2.17]$ \\
\hline \multicolumn{7}{|l|}{ Medicaid Gap } \\
\hline $\mathrm{NO}-1$ & $32.7 \%$ & 1561 & 1.00 (referent) & 1.00 (referent) & 1.00 (referent) & 1.00 (referent) \\
\hline YES-2 & $67.3 \%$ & 3213 & $1.89[1.66,2.16] *$ & $5.8[4.01,8.44] *$ & $1.47[1.27,1.7] *$ & $1.37[1.18,1.6] *$ \\
\hline \multicolumn{7}{|l|}{$\begin{array}{l}\text { Last check up more than a } \\
\text { year ago }\end{array}$} \\
\hline \multicolumn{7}{|l|}{ Above-poverty } \\
\hline $\mathrm{NO}-1$ & $79.9 \%$ & 5154 & 1.00 (referent) & 1.00 (referent) & 1.00 (referent) & 1.00 (referent) \\
\hline YES-2 & $20.1 \%$ & 1294 & $0.36[0.24,0.54] *$ & $0.35[0.22,0.55] *$ & $1.7[1.54,1.9] *$ & $1.33[1.16,1.53] *$ \\
\hline \multicolumn{7}{|l|}{ Traditional Medicaid } \\
\hline $\mathrm{NO}-1$ & $76.4 \%$ & 38826 & 1.00 (referent) & 1.00 (referent) & 1.00 (referent) & 1.00 (referent) \\
\hline YES-2 & $23.6 \%$ & 11991 & $0.65[0.61,0.69] *$ & $1.78[0.67,4.71]$ & $1.56[0.97,2.52]$ & $1.18[0.64,2.17]$ \\
\hline \multicolumn{7}{|l|}{ Medicaid Gap } \\
\hline $\mathrm{NO}-1$ & $46 \%$ & 2068 & 1.00 (referent) & 1.00 (referent) & 1.00 (referent) & 1.00 (referent) \\
\hline YES-2 & $54 \%$ & 2427 & $1.07[0.94,0.1 .22]$ & $0.24[0.17,0.35] *$ & $1.47[1.27,1.7] *$ & $1.37[1.18,1.6] *$ \\
\hline \multicolumn{7}{|l|}{$\begin{array}{l}\text { Could not see doctor due to } \\
\text { cost }\end{array}$} \\
\hline \multicolumn{7}{|l|}{ Above-poverty } \\
\hline $\mathrm{NO}-1$ & $76.6 \%$ & 5129 & 1.00 (referent) & 1.00 (referent) & 1.00 (referent) & 1.00 (referent) \\
\hline YES-2 & $23.4 \%$ & 1567 & $0.45[0.4,0.5] *$ & $0.60[0.48,0.75] *$ & & \\
\hline \multicolumn{7}{|l|}{ Traditional Medicaid } \\
\hline $\mathrm{NO}-1$ & $81.6 \%$ & 1210 & 1.00 (referent) & 1.00 (referent) & 1.00 (referent) & 1.00 (referent) \\
\hline YES-2 & $18.4 \%$ & 273 & $0.55[0.4,0.76] *$ & $0.52[0.35,0.78] *$ & & \\
\hline \multicolumn{7}{|l|}{ Medicaid Gap } \\
\hline $\mathrm{NO}-1$ & $48.1 \%$ & 2350 & 1.00 (referent) & 1.00 (referent) & 1.00 (referent) & 1.00 (referent) \\
\hline YES-2 & $51.9 \%$ & 2539 & $0.37[0.32,0.42] *$ & $0.38[0.32,0.44] *$ & & \\
\hline \multicolumn{7}{|l|}{ Age } \\
\hline \multicolumn{7}{|l|}{ Above-poverty } \\
\hline Age $(<=25)-1$ & $10.7 \%$ & 718 & 1.00 (referent) & 1.00 (referent) & 1.00 (referent) & 1.00 (referent) \\
\hline Age $(>25$ and $<=44)-2$ & $23.4 \%$ & 1574 & $0.26[0.2,0.35] *$ & $0.44[0.28,0.67] *$ & $0.26[0.2,0.35] *$ & $0.26[0.19,0.35] *$ \\
\hline Age $(>44$ and $<=55)-3$ & $17.8 \%$ & 1197 & $0.11[0.08,0.14] *$ & $0.30[0.2,0.47] *$ & $0.11[0.08,0.14] *$ & $0.11[0.08,0.15] *$ \\
\hline Age $(>55)-4$ & $48.1 \%$ & 3237 & $0.15[0.11,0.2] *$ & $0.23[0.15,0.36] *$ & $0.15[0.11,0.2] *$ & $0.08[0.06,0.11] *$ \\
\hline \multicolumn{7}{|l|}{ Traditional Medicaid } \\
\hline Age $(<=25)-1$ & $3.9 \%$ & 58 & 1.00 (referent) & 1.00 (referent) & 1.00 (referent) & 1.00 (referent) \\
\hline Age $(>25$ and $<=44)-2$ & $12.6 \%$ & 187 & $0.0[0.0,0.0]$ & $0.0[0.0,0.0]$ & $0.0[0.0,0.0]$ & $0.0[0.0,0.0]$ \\
\hline Age $(>25$ and $<=44)-3$ & $9.4 \%$ & 140 & $0.0[0.0,0.0]$ & $0.0[0.0,0.0]$ & $0.0[0.0,0.0]$ & $0.0[0.0,0.0]$ \\
\hline Age $(>55)-4$ & $74.2 \%$ & 1105 & $0.0[0.0,0.0]$ & $0.0[0.0,0.0]$ & $0.0[0.0,0.0]$ & $0.0[0.0,0.0]$ \\
\hline Medicaid Gap & & & & & & \\
\hline Age $(<=25)-1$ & $10.6 \%$ & 519 & 1.00 (referent) & 1.00 (referent) & 1.00 (referent) & 1.00 (referent) \\
\hline Age $(>25$ and $<=44)-2$ & $47.3 \%$ & 2321 & $0.55[0.42,0.73] *$ & $0.58[0.42,0,8] *$ & $0.55[0.42,0.73] *$ & $0.51[0.38,0.69] *$ \\
\hline Age $(>25$ and $<=44)-3$ & $21.0 \%$ & 1032 & $0.28[0.21,0.37] *$ & $0.41[0.29,0.57] *$ & $0.28[0.21,0.37] *$ & $0.28[0.2,0.38] *$ \\
\hline Age $(>55)-4$ & $21.2 \%$ & 1039 & $0.21[0.16,0.28] *$ & $0.32[0.22,0.45] *$ & $0.21[0.16,0.28] *$ & $0.18[0.14,0.25] *$ \\
\hline Education & & & & & & \\
\hline Above-poverty & & & & & & \\
\hline Education (College Graduate) & $45.1 \%$ & 3033 & 1.00 (referent) & 1.00 (referent) & 1.00 (referent) & 1.00 (referent) \\
\hline $\begin{array}{r}\text { Education (High School } \\
\text { Graduate/GED) } \\
\end{array}$ & $32.1 \%$ & 2157 & $0.61[0.54,0.69] *$ & $0.81[0.63,1.02]$ & $0.61[0.54,0.69] *$ & $0.8[0.68,0.93] * *$ \\
\hline $\begin{array}{r}\text { Education (Did not finish High } \\
\text { School) }\end{array}$ & $22.7 \%$ & 1528 & $0.42[0.37,0.48] *$ & $0.71[0.55,0.92] *$ & $0.42[0.37,0.48] *$ & $0.63[0.53,0.75] *$ \\
\hline Traditional Medicaid & & & & & & \\
\hline Education (College Graduate) & $44.2 \%$ & 658 & 1.00 (referent) & 1.00 (referent) & 1.00 (referent) & 1.00 (referent) \\
\hline $\begin{array}{r}\text { Education (High School } \\
\text { Graduate/GED) }\end{array}$ & $34.4 \%$ & 513 & $0.7[0.51,0.96] * *$ & $0.62[0.42,0.92] *$ & $0.7[0.51,0.96] * *$ & $0.86[0.48,1.54]$ \\
\hline $\begin{array}{r}\text { Education (Did not finish High } \\
\text { School) }\end{array}$ & $21.4 \%$ & 319 & $0.61[0.43,0.87] *$ & $0.6[0.38,0.95] *$ & $0.61[0.43,0.87] *$ & $0.62[0.33,1.17]$ \\
\hline Medicaid Gap & & & & & & \\
\hline Education (College Graduate) & $28.6 \%$ & 1400 & 1.00 (referent) & 1.00 (referent) & 1.00 (referent) & 1.00 (referent) \\
\hline $\begin{array}{r}\text { Education (High School } \\
\text { Graduate/GED) }\end{array}$ & $34.1 \%$ & 1673 & $0.87[0.74,1.03]$ & $0.84[0.68,1.02]$ & $0.87[0.74,1.03]$ & $0.88[0.73,1.06] *$ \\
\hline $\begin{array}{r}\text { Education (Did not finish High } \\
\text { School) }\end{array}$ & $37.3 \%$ & 1830 & $0.62[0.53,0.73] *$ & $0.63[0.52,0.78] *$ & $0.62[0.53,0.73] *$ & $0.72[0.6,0.86] *$ \\
\hline
\end{tabular}


$* \mathrm{p}<0.001 ; * * \mathrm{p}<0.05$

Note: $\mathrm{a}$ - not adjusted for any other variable; $\mathrm{b}$ - adjusted for all other variables simultaneously; $\mathrm{c}$ - not adjusted factors in PCA; $d$ - adjusted for all other factors simultaneously.

\section{Availability of data and materials}

The datasets generated and analyzed during this study are available from the corresponding author on reasonable request.

\section{Reference}

1. Serban, N. (2020). Healthcare system access: measurement, inference, and intervention (First edition.). Wiley.

2. Schembri S, Ghaddar S. The Affordable Care Act, the Medicaid Coverage Gap, and Hispanic Consumers: A Phenomenology of Obamacare. Journal of Consumer Affairs. 2018;52(1):138-165. doi:10.1111/joca.12146 3. Michener JD. Politics, Pandemic, and Racial Justice Through the Lens of Medicaid. American journal of public health. 2021;111(4):643-646. doi:10.2105/AJPH.2020.306126

4. Medicaid: state and federal actions have been taken to improve children's access to dental services, but gaps remain: report to congressional requesters. (2009). U.S. Govt. Accountability Office.

5. Medicaid and insurance exchanges: additional federal controls needed to minimize potential for gaps and duplication in coverage: report to congressional requesters. (2015). United States Government Accountability Office.

6. Albertson, E. M., Scannell, C., Ashtari, N., \& Barnert, E. (2020). Eliminating Gaps in Medicaid Coverage During Reentry After Incarceration. American Journal of Public Health, 110(3), 317-321. https: //doi-org.libproxy.txstate.edu/10.2105/AJPH. 2019.305400

7. Spencer JC, Gertner AK, Silberman PJ. Health Status and Access to Care for the North Carolina Medicaid Gap Population. North Carolina medical journal. 2019;80(5):269-275. doi:10.18043/ncm.80.5.269

8. Pilon D, El Khoury AC, Manceur AM, et al. Are Medicaid Coverage Gaps Associated with Higher Health Care Resource Utilization and Costs in Patients with Schizophrenia? POPULATION HEALTH MANAGEMENT. 2020;23(3):234-242. doi:10.1089/pop.2019.0147

9. Cohen Ariel. (2017). Beneficiary Groups Oppose Verifying Income Of Those In Medicaid Gap. Inside $C M S, 20(48), 5-6$.

10. Rosenbaum S, Wilensky G. Closing the Medicaid Coverage Gap: Options For Reform. HEALTH AFFAIRS. 2020;39(3):514-518. doi:10.1377/hlthaff.2019.01463

11. Schembri S, Ghaddar S. The Affordable Care Act, the Medicaid Coverage Gap, and Hispanic Consumers: A Phenomenology of Obamacare. Journal of Consumer Affairs. 2018;52(1):138-165. doi:10.1111/joca.12146 12. Clement J, Jacobi M, Greenwood BN. Patient access to chronic medications during the Covid-19 pandemic: Evidence from a comprehensive dataset of US insurance claims. PLoS ONE. 2021;16(4):1-13. doi:10.1371/journal.pone.0249453

13. Gong $\mathrm{X}(1)$, Lin $\mathrm{Y}(1)$, Zhan $\mathrm{FB}(2)$. Industrial air pollution and low birth weight: a case-control study in Texas, USA. Environmental Science and Pollution Research. 25(30):30375-30389. doi:10.1007/s11356-018-2941-y 14. Martin M, Woodbury D, Glogower Y, Duguid M, Frey B, Ashton M. Within-gap position shapes fifty years of forest dynamics in a temperate hardwood forest in Connecticut, USA. Forest Ecology and Management. 2021;494. doi:10.1016/j.foreco.2021.119311

15. Long M, Ghisari M, Kjeldsen L, et al. Autism spectrum disorders, endocrine disrupting compounds, and heavy metals in amniotic fluid: a case-control study. Molecular Autism. 2019;10(1). doi:10.1186/s13229-018-0253-1 16. Passamonti SM, Cannavò A, Panigada M, et al. Donation after circulatory death (DCD) and liver transplantation: a cohort study. Transplant international: official journal of the European Society for Organ Transplantation. May 2021. doi:10.1111/tri.13919

17. Zixi Chen, Fuqiang Liu, Bin Li, Xiaoqing Peng, Lin Fan, Aijing Luo. Prediction of hot spot areas of hemorrhagic fever with renal syndrome in Hunan Province based on an information quantity model and logistical 
regression model. PLoS Neglected Tropical Diseases. 2020;14(12):e0008939. doi:10.1371/journal.pntd.0008939 18. Yi H( 1 ), Zhao $\mathrm{Y}(1$ ), Zhang $\mathrm{R}(1)$, et al. Comparison of dimension reduction-based logistic regression models for case-control genome-wide association study: Principal components analysis vs. partial least squares. Journal of Biomedical Research. 29(4):298-307. doi:10.7555/JBR.29.20140043

19. Wang, Y. et al. (2019) 'Multiple metal concentrations and gestational diabetes mellitus in Taiyuan, China', Chemosphere, 237. doi: 10.1016/j.chemosphere.2019.124412.

20. Tápanes, F J, M Vásquez, R Ramírez, C Matheus, M A Rodríguez, and N Bianco. 2000. "Cluster Analysis of Antinuclear Autoantibodies in the Prognosis of SLE Nephropathy: Are Anti-Extractable Nuclear Antibodies Protective?" Lupus 9 (6): 437-44. doi:10.1191/096120300678828604.

21. Srinivas, K. ( 1 ), Madhukar Rao, G. ( 1 ), Vengatesan, K. ( 2 ), Shivkumar Tanesh, P. ( 2 ), Kumar, A. ( 3 ), \& Yuvaraj, S. ( 4 ). (n.d.). An implementation of subsidy prediction system using machine learning logistical regression algorithm. Advances in Mathematics: Scientific Journal, 9(6), 3407-3415. https: //doi-org.libproxy.txstate.edu/10.37418/amsj.9.6.21

22. Qiu, J. L. , Zheng, J. N. , \& Zhang, Y. . (2005). Application of modified logistic regression model in the analysis of epidemiology. China Tropical Medicine.

23. Horowitz LM, de Sales French R. Interpersonal problems of people who describe themselves as lonely. Journal of Consulting and Clinical Psychology. 47(4):762-764. doi:10.1037/0022-006X.47.4.762

24. Domènech-Abella J, Switsers L, Mundó J, Dierckx E, Dury S, De Donder L. The association between perceived social and physical environment and mental health among older adults: mediating effects of loneliness. Aging \& Mental Health. 2021;25(5):962-968. doi:10.1080/13607863.2020.1727853

25. Midi H, Sarkar SK, Rana S. Collinearity diagnostics of binary logistic regression model. Journal of Interdisciplinary Mathematics. 13(3):253-267. doi:10.1080/09720502.2010.10700699

26. Anderson LJ, Shekelle P, Keeler E, et al. The Cost of Interventions to Increase Influenza Vaccination: A Systematic Review. American Journal of Preventive Medicine. 2018;54(2):299-315. doi:10.1016/j.amepre.2017.11.010 27. Nichol KL. Cost-benefit analysis of a strategy to vaccinate healthy working adults against influenza. Archives of internal medicine. 2001;161(5):749-759. doi:10.1001/archinte.161.5.749

28. Lopez-Santana M. Fragmented Democracy: Medicaid, Federalism, and Unequal Politics. PUBLIUS-THE JOURNAL OF FEDERALISM. 2020;50(1). doi:10.1093/publius/pjz026

29. Anne Schneider, Helen Ingram. Social Construction of Target Populations: Implications for Politics and Policy. The American Political Science Review. 1993;87(2):334-347. doi:10.2307/2939044

30. Sommers BD, Baicker K, Epstein AM. Mortality and access to care among adults after state Medicaid expansions. The New England journal of medicine. 2012;367(11):1025-1034. doi:10.1056/NEJMsa1202099

31. Preker, A. S. (2018). Financing universal access to healthcare: a comparative review of landmark legislative health reforms in the OECD. World Scientific Publishing, Co. Pte. Ltd.

32. Cu A, Meister S, Lefebvre B, Ridde V. Assessing healthcare access using the Levesque's conceptual framework- a scoping review. International Journal for Equity in Health. 2021;20(1):1-14. doi:10.1186/s12939-021-01416-3

33. Ayenew LG, Hoelscher MA, Emshoff JG, Kidder DP, Ellis BA. Evaluation of the public health achievements made by projects supported by a federal contract mechanism at the Centers for Disease Control and Prevention (CDC), USA. Evaluation and Program Planning. 2021;88. doi:10.1016/j.evalprogplan.2021.101949 Acknowledgements

The authors thank Dr. F. Benjamin Zhan, for his instructive advice and useful suggestions on this paper. Funding

This research received no external funding.

Authors' Information.

\section{Affiliations}

Department of Geography, Texas State University, San Marcos, TX, USA; Xiu Wu;

School of Resource and Environmental Science, Wuhan University, Wuhan 430079, China. Jinting Zhang, associate professor.

\section{Authors' contributions}

Conceptualization and methodology, X.W., and J.Z.; investigation, resources, and data curation, X.W.; writing - original draft preparation, X.W.; writing - review and editing, J.Z.; supervision and project administration, J.Z.; All authors have read and agreed to the published version of the manuscript.

Corresponding author

Correspondence to Xiu $\mathrm{Wu}$ 


\section{Ethics declarations}

Ethical Approval and Consent to participate

Not Applicable for studies not involving humans or animals.

Consent for publication.

Not applicable.

Competing interests

The authors declare that they have no competing interest. 